\title{
Mistakes in Communication: Modus Operandi in Learning, Polishing and Honing Our Communication
}

\author{
Nagen. B. Patnaik \\ Department Of English. \\ Temple City Institute Of Technology \& Engineering (TITE),Bhubaneswar, Odisha
}

\begin{abstract}
In today's competitive world, the importance of English, particularly, Spoken English matters a lot. Fluency in English is absolutely vital in order to succeed in the rat-race of the modern and professional world. In the arena of academics, mistakes are perceived as bad and to be avoided. In the early phase of our life, we are taught that mistakes are bad and embarrassing. In fact, mistakes are simply opportunities to learn something new. The more mistakes a person makes, the greater chance they will have of succeeding on their next effort. In other words, mistakes provide a platform of opportunities. The key, however, is to learn from the mistakes and never repeat the same mistake. It is not wise to try to force speech before the learner is ready. The result is that most students speak English very slowly- with no confidence and fluency. One should focus on listening and be patient. Speak only when you are ready to speak-when it happens easily and naturally. Students and teachers often focus on mistakes and they correct mistakes. They try to speak perfectly. No one, however, is perfect. Instead of focusing on the negative aspects, one has to focus on the intelligibility of communication. The objective is to communicate ideas, information, and feelings in a clear and comprehensible way. The proposed paper emphasizes and states the mistakes which occur particularly in spoken and written English. Furthermore, the paper tries to find out the mistakes and to present a solution for the refinement and rectification to make our communication intelligible and comprehensible to others.
\end{abstract}

Keywords: Spoken and Written English; mistakes; communication; Odiya, Assamese, Guajarati speakers of English; nonverbal cues.

\section{Effective Communication Paves the Way}

\section{Introduction}

The ability to communicate effectively is really very important in different spheres such as education, work, business and what not. We have to communicate effectively in order to create and facilitate good relationships. Furthermore, effective communication shows the path of success. Communication is the process of transferring signals, messages between a sender and a receiver through various methods such as written words, nonverbal cues, and spoken words. It may also be defined as giving, receiving or exchanging information, opinions, ideas by writing; speech or visual means, so that the material communicated is completely understood by everyone concerned. It is also the mechanism that we use to establish and adapt relationships. The way we communicate ideas, views, feelings, etc..., reflects our attitude and personality towards others and it is our communication which plays the key role in recognizing our professionalism.

We have to pursue certain major steps to fine-tune and polish our communication skill and to make it effective and intelligible.

- Demonstrate constructive attitudes. The attitudes that we show while communicating have a huge impact on the way we interact with others. We have to be honest, patient, optimistic, sincere, and respectful of others. We need to be sensitive to other people's feelings, and believe in others' competence.

- Build eye contact. Eye contact conveys interest, and encourages others to be interested in you in return. While giving a speech in front of several people, holding the eyes of different members of the audience can personalize what you are saying and maintain attention.

- Be familiar with your body language. Body language speaks a volume than a mouthful of words. For instance, an open stance with arms relaxed at your sides tells that you are approachable and open to hearing what they have to say. On the other hand, arms crossed and shoulders hunched, suggest disinterest in conversation or unwillingness to communicate. Appropriate posture and an approachable stance can make even difficult conversations flow more smoothly. 
- Be confident to present ideas. We can make our contributions worthwhile by creating confidence in our mind. Take time to be aware of your opinions and feelings so you can adequately convey them to others. Individuals who are hesitant to speak because they do not feel their input would be worthwhile need not fear; what is important or worthwhile to one person may not be to another and may be more so to someone else. In a world so very big, someone is bound to agree with you, or to open your eyes to an even deeper perspective.

- Make your speech clear. An appropriate tone and volume can inform listeners that you mean what you say; what you are saying is worth hearing. Using proper modulation helps ensure that your listeners hear exactly what you are saying, and reduces possibilities for misunderstanding.

- Develop effective listening skills. In order to make our spoken communication effective, we should develop our listening skill. We must listen to the other person's words and engage in communication on what the other person is speaking about. Because, listening skill is considered to be the mother of all the skills.

\section{Speaking: A Vehicle for Effective Communication}

Undoubtedly, English language is a vehicle for both national and international communication. In order to meet the demands of modern society, we need to pay more attention to the development of our competence and focus on a more effective and successful method. We have to gain control over a number of different elements, such as accent, vocabulary, grammar, style, etc. of the language to become an effective speaker of English. From the communicative point of view, speaking has two major categories - accuracy, which involves the correct use of vocabulary, grammar and pronunciation practiced through controlled and guided activities; and fluency, considered to be the ability to keep going when speaking spontaneously. As non-native teachers of English as a Foreign Language (EFL), and especially phonetics teachers, we are realistic - and self-critical - enough to know that few of our students, or, for that matter, few of us, will ever sound exactly like native English speakers. But we do have to make sure that the model prospective teachers set to following generations of pupils in our schools is not too far from what a native speaker sounds like. In this regard, we rightly expect a high degree of precision in the phonetic realization of phonemes and confident handling of accentual and intonation patterns of English. J.D.O'Connor once put it: "Make no mistake; your aim must be to acquire a perfect English pronunciation. You will almost certainly not succeed in this aim because it requires [...] a very rare gift; but unless this is your aim you will not make all the progress of which you are capable; keep working towards perfection until you are quite sure that it is neither necessary nor profitable for you to continue. Then you will have done yourself justice."

According to Martyn Bygate (1987: 3), "In order to achieve a communicative goal through speaking, there are two aspects to be considered - knowledge of the language, and skill in using the language." It is not enough to possess a certain amount of knowledge, but a speaker of the language should be able to use this knowledge in different situations.

"We do not merely know how to assemble sentences in the abstract: we have to produce them and adapt the circumstances. This means making decisions rapidly, implementing them smoothly, and adjusting our conversation as unexpected problems appear in our path."

So far as English grammar is concerned, people often make mistakes while speaking. For instance, I have heard many of my colleagues say "I am belongs/ I belongs/ I am belonging to India" instead of saying "I belong to India." The phrases "I am belongs/ I belongs" are ungrammatical. As per Standard English grammar, "Belong" is a stative verb which does not take the -ing form. Some more common mistakes that people often make are as follows:

\section{"It was a blunder mistake" instead of "It was a blunder," or "It was a big mistake." \\ "It would have been more better" instead of "It would have been better." \\ "Your hairs are looking silky today" instead of "Your hair is looking silky today."}

My students say "can I get in/come in Sir/Madam; Get in Sir/Madam/" instead of saying "May I come in Sir/Madam". Because while asking for permission the sentence "May I come in Sir/Madam" is considered most polite in Formal English. That's why continuous effort is put forth to make the students aware of formal English and Professionalism.

Phonetics, Sounds of English, is another major area where people commit big mistakes. People are least concerned with the sounds of English. In fact, it happens due to less knowledge on phonetics and this leads to poor communication intelligibility. In order to achieve proper articulation of the phonemes of English and to make it standard, one should learn the IPA (International Phonetic Alphabet) symbols: the consonant, vowel phonemes, word stress, intonation pattern and RP (Received Pronunciation). By 
learning sounds of English, we can bring charm to our spoken English and make our communication more comprehensible.

As we know that the 26 letters in the English alphabet produce 44 Sounds or phonemes. They are further divided into 24 Consonant phonemes and 20 Vowel phonemes. Vowels are again divided into 12 Monophthongs and 8 Diphthongs. Monophthongs are also subdivided into 7 Short and 5 Long vowels. Speech is articulated by the vocal organs. Every language has a definite set of phonemes, and every phoneme can be described with reference to the vocal organ that is used to articulate it. In this way, phonemes occurring in different languages can be compared, and foreign language learners can be helped to overcome pronunciation problems that arise from differences between languages. When we are dealing with English language, we have to remember that there is no one-to-one relationship between the letters of the alphabet and the sounds they represent. For instance, consider the different ways the letter ' $\mathrm{e}$ ' is pronounced in the word re-entered: it has 4 different pronunciations, including one silent letter. The letter string "-ough" can be pronounced in different ways as in bough, bought, cough, through. "A truly acceptable pronunciation is one that allows the listener to understand the content of a message without being distracted by its form." The pronunciation of English varies from one country to another and there are marked pronunciation features associated with English spoken in important English speaking countries like UK, USA, Canada, etc. One particular accent, called Received Pronunciation (RP) has come to be accepted as the standard in the United Kingdom.

The following figure is a non-verbal representation of Sounds of English and their classifications.

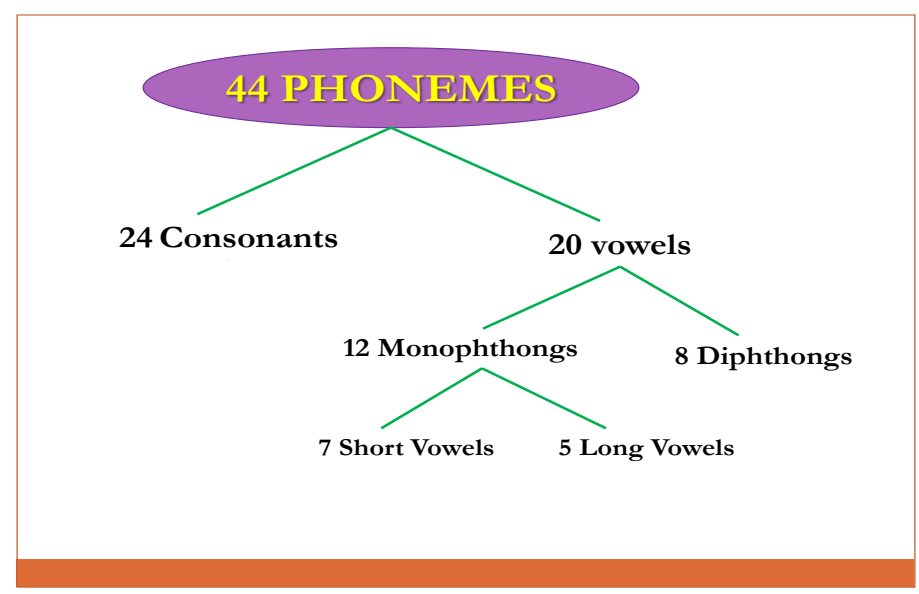

Figure-1: Phonemes and Classification

Let us focus on some of the major problems that we face while articulating words in isolation and in connected speech. "Some Odiya, Assamese, Bengali, and Gujarati speakers of English in India do not always maintain the distinction between /i:/and /I/.They replace /i:/ by /I/ and thus cannot distinguish between pairs like eat and it; feel and fill; sleep and slip. It is necessary to keep the two phonemes /i:/and /I/ separate and maintain the difference of quality. It is also necessary to give /i:/ adequate length. Some Odiya speakers of English are unable to articulate the phoneme $/ \square: /$ correctly. Thus they articulate the words like taught /t $\square: t /$, caught $/ \mathrm{k} \square: t /$ as $/ \mathrm{t} \square \mathrm{t} /$ and $/ \mathrm{k} \square \mathrm{t} /$, which creates problem in intelligibility for the listeners." (Bansal, R.K. \& J.B. Harrison (1998) Spoken English for India, Orient Longman, Chennai). Even the word Pronunciation is articulated in a wrong way. People pronounce it as /pr $\square$ næunsies $\square \mathrm{n} / \mathrm{instead}$ of $/ \mathrm{pr} \square \mathrm{n} \wedge \mathrm{n} \int \mathrm{ieI}[\mathrm{n} /$. People from Bihar articulate the words like School, Scooter, State, and Status as Ischool. Iscooter, Istate, Istate which create problems in understanding them. In order to avoid these problems, we have to learn and articulate the phonemes correctly. We can make our oral communication effective only by identifying and rectifying the mistakes.

\section{Be Professional In Speaking}

In the Professional world, we have to maintain our professionalism in all spheres. We should try to be as objective as possible during any professional speaking situation like a seminar, a workshop, a meeting, or a discussion. In order to achieve objectivity and to make communication bias-free, we have to avoid using sexist language. Plural subjects may be used instead of singular to avoid being sexist in language. The words such as men, women, mankind, chairman, policeman, etc... may be avoided. Instead, people, human beings, 
chairperson/chair, police personnel, etc..., may be used. Secondly, reference to irrelevant differences based on caste or religion may be avoided. For instance, the usage of the phrases like a 'Muslim Lawyer', a 'Bengali Teacher', a 'Female journalist, and so on reflects an unconscious bias as the classification is based on irrelevant differences. In fact, a professional has to reflect an attitude that does not hurt and offend the listeners.

\section{Written Communication: The Next Main Concern and Priority}

So far as writing is concerned, it is the toughest skill to be learnt. We should perform a lot of home works to achieve perfection in written communication. It can be defined as the art of forming letters and characters on paper, stone, or other material, for the purpose of recording the ideas or of communicating them to others by visible signs. It is the representation of language in a textual medium through the use of a set of signs or symbols. In oral communication, listeners can make out what speaker is trying to say, but in written communication, text matter in the message is a reflection of your thinking. Writing skills are an important part of communication. Regardless of what level of hierarchy you are at in an organization, writing is a valuable skill. Managers are expected to write reports, emails, memos and letters which their subordinates are supposed to read. If this written communication is badly structured and written, the subordinates will waste time trying to interpret it. Badly written communication is also open to misinterpretation. In order for a manager's career to prosper, they need to possess and fine tune this important skill-set. The significance of writing skills cannot be overemphasized because it is so important for students of all kinds and professionals in all fields. As a professional, a person needs effective writing skills because one has to write examination answers, project reports, lab reports, summaries, synopsis, etc... Professionals are required to write business letters, memos, email messages, reports, proposals, professional summaries, and so on. Both professionals and students need excellent writing skills to survive and excel in their pursuits as there is hardly any academic or professional activity that does not require writing skills.

The ability to write effective sentences is essential for success in technical communication because writing anything primarily involves writing sentences. Whether it is a long technical report or a brief e-mail message, sentences have to be written and the effectiveness of the writing will depend on the effectiveness of the sentences. Inappropriate, loose, and awkward sentences can never make effective writing. Therefore, it is important to learn to write correct and effective sentences before learning to compose serious messages.

Written communication offers a permanent record for future use and it also gives an opportunity to employees to put up their comments or suggestions in writing. The following key features focus on the importance of writing:

- Written communication is permanent

- Written communication is easier to understand

- Written communication can be composed in advance

- Written communication leaves lasting impression

Developing effective communication and writing skills is critically important in advancing our career or profession. Professionals who write well are way ahead of others on all career paths. Developing effective writing skills is an important step for professionals on all career paths. A poorly and badly written email, memo, or letter can leave important people confused, angry, or even misinformed if the writing which comes to them is not effectively written. Not only the message received be perceived differently than the intended message, but the reader forms opinions that can have long lasting effects in the workplace. Effective writing skills are central both in higher education and the world of work that follows. Writing well is a major cognitive challenge, because it is at once a test of memory, language, and thinking ability. It demands rapid retrieval of domainspecific knowledge about the topic from long-term memory.

As a professional, one has to be very meticulous about written communication. We have to write various business letters, reports, proposals, resume, email messages and what not. In order to write these business documents we should follow certain instruction to give them a formal look. Secondly, we must be aware of the proper and apt vocabulary to strengthen the written communication. Even in writing a simple application, people often commit mistakes. For instance, when I correct my students' application writing, I find that they write "To - The Principle/principal" instead of "To - The Principal". So far as the complimentary closing of the letter is concerned, they write "your's faithfully/ sincerely" instead of "Yours faithfully/ sincerely". These are the mistakes that often occur in their writing. But once they are told, they correct the mistakes and try to make their writing standard and formal. Further, while writing a formal email message, we often do mistakes. Because we are acquainted with writing messages to friends, kith and kin in an informal way and this attitude is also reflected in writing formal messages. For instance, the words like "buddy, dude, what's up, $\mathrm{n}$ (and), gd mrng (good morning), hi, $\mathrm{h} \mathrm{r}$ u (how are you), etc. are frequently used in informal or friendly messages. But if these words and phrases are used in formal situations, then it takes away the charm of 
professionalism. Thus, it is the prime duty of the writer to make the writings error free for clear understanding and intelligibility of the readers.

\section{CONCLUSION}

To sum up, I would like to focus on the fact that in order to make communication effective and error free, we have to be very vigilant at conveying the message. As we know that communication is a two-way process, which demands the satisfaction of the sender and the receiver. Mistakes teach us a lot. But if mistakes are frequently repeated, then it leads to communication breakdown, confusion and misunderstanding. In order to achieve professionalism, one has to be very meticulous about the lucidity of the message as it paves the way to the path of success.

\section{References}

[1]. Alex, K. 2009. Soft Skills: Know Yourself \& Know the World. S. Chand, New Delhi.

[2]. Bansal, R.K. \& J.B. Harrison. 1998. Spoken English for India, Orient Longman, Chennai.

[3]. Bygate, M. 1987. Speaking. Oxford University Press.

[4]. Connor, J.D.O, 1967. Better English Pronunciation, Cambridge University Publication

[5]. Kellogg, R. T. 2001. Long-term working memory in text production. Memory \& Cognition, 29, 43-52.

[6]. Rizvi, M.A. 2005. Effective Technical Communication, Tata McGraw Hill, New Delhi.)

[7]. Sauer.W. Some recent developments in Standard British English Pronunciation and the Teaching of EFL, University of Heidelberg.

\section{Web references}

[8]. http://www.wikihow.com/Develop-Good-Communication-Skills 